\title{
CENTRALLY INDUCED VASOPRESSOR AND SYMPATHETIC NERVE RESPONSES TO CARBACHOL IN RATS
}

\author{
Atsushi Inoue, M.D., Hakuo Takahashi, M.D., Hiroshi OKajima, M.D. \\ Seitchi Yoneda, M.D., Susumu Sasaki, M.D., Kazuo Takeda, M.D. \\ Manabu Yoshimura, M.D., Masao Nakagawa, M.D. \\ AND Hamao IJICHI, M.D.
}

\begin{abstract}
Blood pressure rose when carbachol was injected into the cerebral ventricles in conscious rats, but the heart rate fell. When rats were later anesthetized with urethane to allow recording of abdominal sympathetic nerve activity, carbachol injected similarly produced the following biphasic responses: initial vasodepression followed by a sustained pressor phase accompanied by corresponding changes in peripheral sympathetic nerve activity. The heart rate was transiently suppressed following the injection. Spinal section abolished the initial hypotensive phase and accompanying bradycardia and made the response purely pressor. By contrast, intravenous injections elicited purely vasodepressor responses. Thus, carbachol administered centrally caused vasopressor responses possibly via both activation of sympathetic vasomotor centers and a release of pituitary hormones. Since anesthesia attenuated the pressor responses and made them biphasic, these results indicate that central cholinergic mechanisms are inhibited during anesthesia and that a sympathoinhibitory mechanism of cholinergic receptors exists behind the pressor responses, as disclosed during anesthesia.
\end{abstract}

$I^{\mathrm{N}}$ NTRACEREBROVENTRICULAR (ICV) injections of cholinergic agonists are known to cause pressor responses in several species., 2,3,4 Since acetylcholine $(\mathrm{ACh})$, along with choline acetylase and choline esterase (the enzymes concerned in its synthesis and degradation $)^{5}$ and cholinergic pathways are present in different regions of the brain, ${ }^{6}$ a neurotransmitter role has been suggested for $\mathrm{ACh}$ on thermoregulation, ${ }^{4,7}$ behavior ${ }^{8}$ and cardiovascular regulation ${ }^{1}$ in the central nervous system. Carbachol, a cholinergic agonist re-

Key Words:

Cholinergic mechanism

Sympathetic nerve activity

Blood pressure

Intracerebroventricular injection

Vasopressin sistant to hydrolysis by acetylcholinesterase, produces drinking,, 10 ADH release ${ }^{1,11,12}$ and natriuresis 13,14 when injected intracranially in rats. Therefore, in connection with the hypertensive effects, 2 components are assumed to be involved: pituitary hormonal factors $1,11,12$ (possibly ADH release) and central activation of sympathetic nerve outflow, 15 Nevertheless, central sympathetic nerve activity influenced by ICV injections of carbachol has not yet been fully elucidated.

This paper focuses on the changes of peripheral sympathetic nerve activity caused by carbachol injected ICV in rats.

\section{MATERIALS AND METHODS}

Sixty-six 12-week-old female Wistar rats were

(Received February 26, 1983; accepted September 14, 1983)

2nd Department of Medicine, Kyoto Prefectural University of Medicine, Kamikyo-ku, Kyoto, Japan

Mailing address: Hakuo Takahashi, M.D., 2nd Department of Medicine, Kyoto Prefectural University of Medicine, Kamikyo-ku, Kyoto 602, Japan 
purchased from Tokushima Breeding Lab. Inc. (Tokushima, Japan). Their average body weight was $235 \pm 7 \mathrm{~g}$. For experiments on conscious rats, cannulas were implanted into a lateral ventricle and an abdominal aorta, and the rats were allowed to recover from surgery for two days. They were then placed in a plastic holder and blood pressure was recorded continuously. In other experiments, rats were anesthetized with urethane $(100 \mathrm{mg} / 100 \mathrm{~g}, \mathrm{IP})$, and a cannula was inserted into the left lateral ventricle for injecting drugs and a catheter into a femoral artery for recording blood pressure, and a bipolar electrode was placed over the abdominal sympathetic nerve bundle for recording nerve firing.

Implantation of Arterial Catheters: Rats were anesthetized with ketamine hydrochloride (40 $\mathrm{mg} / \mathrm{kg}$, IP) while an arterial catheter made of PE-20 and PE-10 tubing according to modification of the method described by Weeks and Jones ${ }^{16}$ was inserted into the abdominal aorta. The other end of the catheter was held in place with wound clips, and the tip was plugged with a stylet. During the experiments, arterial pressure was recorded continuously by connecting the catheter tip to a small volume displacement pressure transducer while saline was being infused $(0.3 \mathrm{ml} / \mathrm{hr})$ through a side arm of the catheter.

Intracerebroventricular Injections: In rats anesthetized with ketamine hydrochloride, a guide cannula (ga 23, stainless steel tubing, 1.5 $\mathrm{cm}$ long with a ga 30 stylet) was inserted into the left lateral ventricle (at stereotaxic coordinates ${ }^{17}+5.6$ anteroposterior, 1.6 lateral and +2.0 dorsoventral, with the upper incisor bar set $5 \mathrm{~mm}$ above the interaural line) and fixed to the skull with screws and dental cement (acrylic resin, Shofu Dental MFG. Co., Kyoto, Japan). Drugs were injected by inserting a injection cannula (ga 30 stainless steel tubing) connected to a 25 $\mu l$ syringe into the guide cannula. The whole system was filled with the solution to be injected and each injection had a volume of $10 \mu \mathrm{l}$ delivered manually in $10 \mathrm{sec}$. After each experiment, methylene blue was injected through the injection cannula to verify correct placement in the lateral ventricle.

Recording of Sympathetic Nerve Activity: The abdominal plexus was exposed through a left lateral abdominal transverse incision, and the inferior nerve bundle emerging from a celiac ganglion was placed over a bipolar stainless steel electrode (uninsulated tips $1 \mathrm{~mm}$ apart). Nerves and electrode tips were immersed in vegetable oil to prevent tissue drying. To reduce noise during nerve recording, spontaneous respiratory movements were abolished by paralyzing skeletal muscle with decamethonium bromide $(0.2 \mathrm{mg}$ / $100 \mathrm{~g}, \mathrm{IV}$ ), and the rat was ventilated with room air by a ventilator (Ealing Corp., South Nattick, MA). Spike potentials were amplified (p-15 preamplifier, Grass Instrument Co., Quincy, Mass., and biophysioamplifier, Sanei Instrument Co., Tokyo, Japan), monitored on a storage oscilloscope (Kikusui Electronics, Tokyo, Japan) and recorded continuously on a magnetic tape together with blood pressure (TEAC Corp., Tokyo, Japan). Tapes were later played back into an amplitude analyzer to delete background noise, and the resulting pulses were fed into a spike counter (Dia Medical System Co., Tokyo, Japan) whose output was digitalyzed and printed out on a recorder (Rectigraph, Sanei Instrument Co.). Integrated nerve activity for one min in the 5 min following the drug injection, was divided by the baseline activity before the injection, and the percent increase of the activity was calculated.

Spinal Sectioning: Rats were anesthetized with urethane, and the spinal cord at the C-1 level was cut by transverse incision of the neck skin during artificial respiration $30 \mathrm{~min}$ before an ICV injection of carbachol. Sham operations without cutting the spinal cord were performed in control rats.

Drug Injections: For ICV bolus injections, carbachol (Sigma Chemical Co., Saint Louis, Mo.) was dissolved in saline $(0.9 \% \mathrm{NaCl})$. Whenever sympathetic nerve activity was recorded, pentolinium tartrate $(0.5 \mathrm{mg} / 100 \mathrm{~g}$, IV, Sigma Chemical Co.) was injected at the end of each experiment to delete residual activity and setting the low window discriminator during playback.

Statistics: Data expressed as average \pm SEM were analyzed using a two tailed t-test for comparing means of independent samples and differences at a 5\% level $(p<0.05)$ or less were considered significant.

\section{RESULTS}

ICV Injections of Carbachol in Conscious Rats: The blood pressure and heart rate were consistently increased following ICV injections of carbachol, and the rats showed hyperactive behavior immediately following the injection which lasted for less than $10 \mathrm{~min}$ : they tried 
TABLE I DOSE-RELATED PRESSOR RESPONSES TO CARBACHOL INJECTED ICV IN CONSCIOUS RATS

\begin{tabular}{ccccc}
\hline $\begin{array}{c}\text { Doses }(\mathrm{ng}) \\
(\mathrm{n})\end{array}$ & $\begin{array}{c}0.1 \\
(6)\end{array}$ & $\begin{array}{c}1.0 \\
(6)\end{array}$ & $\begin{array}{c}10.0 \\
(6)\end{array}$ & $\begin{array}{c}100 \\
(6)\end{array}$ \\
\hline Baseline aortic pressure $(\mathrm{mmHg})$ & $116 \pm 2$ & $118 \pm 2$ & $116 \pm 3$ & $125 \pm 1$ \\
Responses $(\mathrm{mmHg})$ & $+1 \pm 1$ & $+5 \pm 0.4$ & $+23 \pm 0.4$ & $+31 \pm 1$ \\
\hline
\end{tabular}

TABLE II EFFECTS OF ICV INJECTIONS OF CARBACHOL, $1 \mu \mathrm{g}$, IN URETHANE ANESTHETIZED RATS $(n=6)$

\begin{tabular}{llccc}
\hline Variables measured & Baseline & \multicolumn{3}{c}{ Elapsed time (min) } \\
\cline { 3 - 5 } & & 1 & 5 & 15 \\
\hline Blood pressure $(\mathrm{mmHg})$ & $106 \pm 3$ & $-6 \pm 3$ & $+12 \pm 1$ & $+7 \pm 2$ \\
Heart rate (beats/min) & $400 \pm 13$ & $-53 \pm 13$ & $-29 \pm 10$ & $-39 \pm 12$ \\
$\begin{array}{c}\text { Sympathetic nerve activity } \\
\text { (number of spikes/30 sec) }\end{array}$ & $623 \pm 58$ & $-58 \pm 12$ & $+126 \pm 22$ & $+1287 \pm 112$ \\
\hline
\end{tabular}
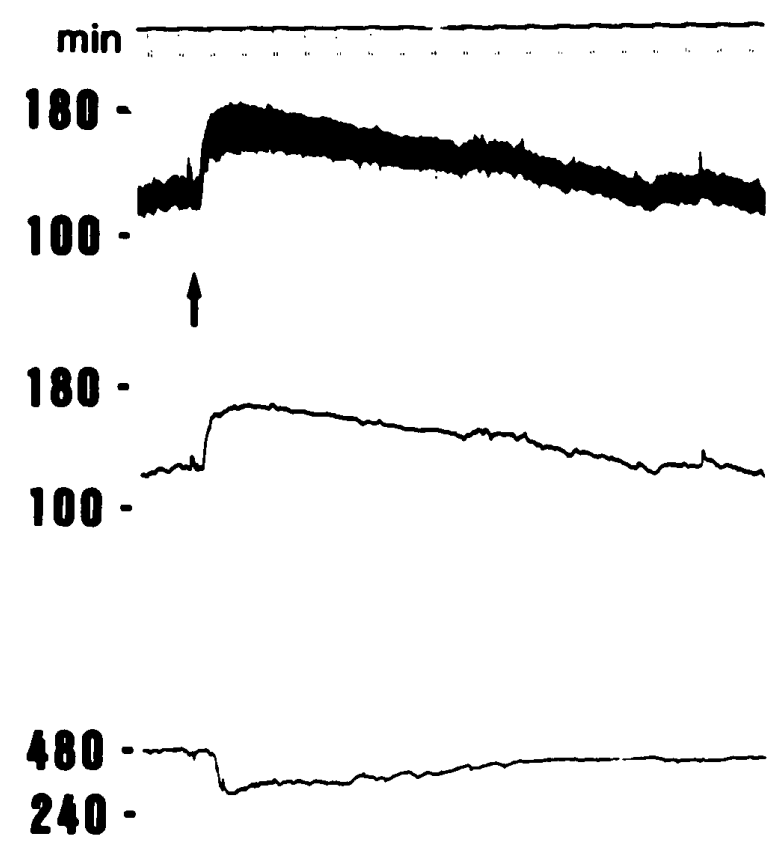

Fig.1. Responses to ICV injection of carbachol, $100 \mathrm{ng}$, in a conscious rat. From top to bottom: phasic aortic pressure $(\mathrm{mmHg})$, mean pressure, and heart rate (beats/min).

vigorously to escape from the holder. And they drank water when it was offered. After injections of $1.0,10$, and $100 \mathrm{ng}$ of carbachol, the blood pressure began to rise within $30 \mathrm{sec}$ and attained peak values $2-3$ min later, and the heart rate began to decrease within $30 \mathrm{sec}$ following the injection with a simultaneous rise in the blood pressure (Fig. 1). Within the dose-range given, the magnitude of the pressor effects was dose-dependent (Table I). On the other hand, injections of the vehicle $(10 \mu$ l of physiological saline without carbachol) affected neither the behavior nor the blood pressure.

Is There Sympathetic Involvement in the Central Responses to Carbachol?: To determine whether differences in sympathetic nerve activity could account for the differences in pressor response to carbachol, ICV injections of carbachol were repeated in urethane anesthetized rats that had been prepared for recording of both blood pressure and abdominal sympathetic nerve activity simultaneously. Although doses of carbachol increased ten fold $(1 \mu \mathrm{g})$ to elicit significant pressor responses, responses were still smaller than those produced by $100 \mathrm{ng}$ of carbachol in concious rats. Carbachol elicited biphasic responses consisting of an initial hypotensive phase followed by a sustained pressor phase, accompanied by corresponding changes in abdominal sympathetic nerve activity. Heart rate decreased in the initial hypotensive phase. Sustained pressor responses reached peak elevations 3-4 min following the injection and then returned to the baseline level $15-20 \mathrm{~min}$ later (Fig. 2, Table II).

Effects of Spinal Sectioning on the Pressor Responses to Carbachol: Since the extent of sympathetic participation could not be de- 
TABLE III EFFECTS OF SPINAL SECTIONING ON THE PRESSOR RESPONSES TO CARBACHOL, $1 \mu \mathrm{g}$, IN URETHANE ANESTHETIZED RATS

\begin{tabular}{cccc}
\hline $\begin{array}{c}\text { Blood pressure } \\
(\mathrm{mmHg})\end{array}$ & $\begin{array}{c}\text { Baseline } \\
\text { (pre-section) }\end{array}$ & $\begin{array}{c}\text { Baseline } \\
\text { (post-section) }\end{array}$ & Responses \\
\hline Sham-operated $(n=6)$ & $116 \pm 3$ & $116 \pm 3$ & $+13 \pm 2$ \\
Spinal sectioned $(n=6)$ & $106 \pm 6$ & $62 \pm 6$ & $+12 \pm 2$ \\
\hline Heart rate (beats $/ \mathrm{min})$ & $474 \pm 5$ & $474 \pm 5$ & $-70 \pm 2$ \\
Spam-operated $(n=6)$ & $446 \pm 15$ & $309 \pm 41$ & $-5 \pm 2^{* *}$ \\
\hline
\end{tabular}

$\left({ }^{* *} p<0.01\right.$ vs sham)
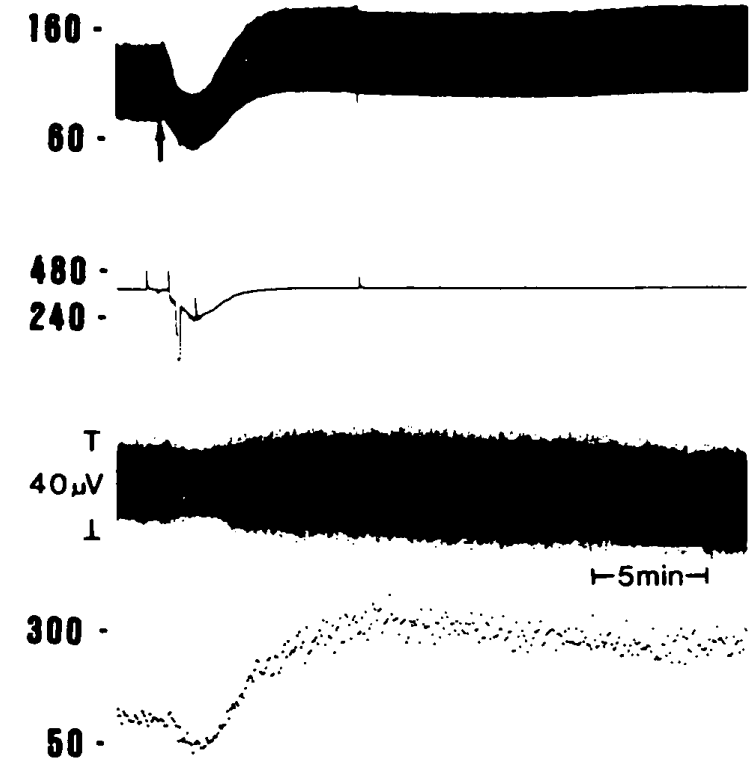

Fig.2. Responses to ICV injections of carbachol, $1 \mu \mathrm{g}$, in an urethane-anesthetized rat. From top to bottom: phasic femoral arterial pressure $(\mathrm{mmHg})$, heart rate (beats/min), original analog signals and histogram (number of spikes/5 sec) of abdominal sympathetic nerve firing.

termined from the results described above, some additional experiments were done to test how the responses to carbachol would be affected by interrupting sympathetic neural pathways between the brain and the spinal cord. The blood pressure fell immediately in all rats as soon as the spinal cord was sectioned at the C-1 level, and the subsequent heart rate also showed in all rats. Although carbachol injected following it elicited biphasic responses, as described above, in the sham-operated rats, carbachol elicited purely pressor responses in the spinal-sectioned rats. Furthermore, bradycardia was never recorded in the spinal-sectioned rats. There were no differences in the magnitude of the pressor responses between sham-operated and spinal sectioned rats (Table III).

Effects of Carbachol Injected Intravenously: To determine the systemic effects of carbachol on blood pressure and sympathetic nerve outflow, carbachol, $1 \mu \mathrm{g}$, was injected through femoral venous catheters in 5 urethane-anesthetized rats. After the bolus injection of carbachol, $1 \mu \mathrm{g}$, blood pressure and heart rate decreased transiently for less than $3 \mathrm{~min}(-37 \pm 3 \mathrm{mmHg}$ and $-126 \pm 14$ beats/min, respectively) while sympathetic nerve activity increased for less than $1 \mathrm{~min}(+278 \pm 22 \%$ from the baseline).

\section{DISCUSSION}

A very small amount of carbachol injected ICV elicited marked vasopressor responses, hyperactive behavior and thirst in the conscious rats. These effects were presumably produced by the pharmacological action of carbachol, because dose-related increases in both blood pressure and behavioral excitation were recorded. Rapid increases in blood pressure following ICV injections could not be explained by the releases of humoral factors like pituitary hormones, but by neural events, i.e. increased sympathetic nerve outflow. However, contrary to our expectations, the recorded sympathetic nerve activity was suppressed transiently immediately after the injection, as the heart rate fell in urethane-anesthetized rats. The magnitude of the pressor responses was less than one tenth that produced in conscious rats. These results suggest that urethane anesthesia inhibits the central cholinergic mechanisms. But the opposite initial 
responses in the conscious awake and anesthetized rats cannot be explained solely by the inhibition. Because carbachol elicited marked behavioral excitation in awake rats, the initial pressor response may be attributed to the motor excitation. Nevertheless, sympathetic nerve activity increased in the sustained pressor phase. Because increases in sympathetic nerve activity were too small to explain the whole pressor responses found in our experiments, such an alternative mechanism as release of pituitary hormones was investigated later by abolishing sympathetic mediation by spinal transection. Then, although the biphasic blood pressure responses was noted after ICV injections of carbachol in the sham-operated rats, purely pressor responses were produced in spinal sectioned rats, in which the magnitude of the pressor responses was the same in both groups. Reduced pressor responses in the spinal-sectioned rats would be expected, because sympathetic neural mediation of the pressor responses seems probable on the basis of the findings described above. This contradiction may have occurred because the pressor responses in the spinalsectioned rats were larger than those in the shamrats due to the augmented vascular reaction to ADH released ${ }^{1}$ or due to the blunted baroreceptor reflexes induced by the markedly lowered baseline blood pressure.

The theory that the responses to carbachol injected ICV are of central origin is supported by the finding that intravenous injections of carbachol produced quite different blood pressure and sympathetic nerve responses. Carbachol injected intravenously produced purely depressor responses accompanied by transient increases in sympathetic nerve activity presumably due to baroreceptor reflexes.

Central pressor effects of carbachol have been well documented showing involvement of both the activated sympathetic vasomotor center and release of $\mathrm{ADH}$, 2,18,19 but direct measurement of the sympathetic nerve activity following ICV injections of carbachol has never been done before so far as we know. We found here that carbachol injected ICV produced biphasic blood pressure responses accompanied by corresponding sympathetic nerve discharge in urethane-anesthetized rats. Although previous studies indicate that central cholinergic mechanisms are exclusively of pressor effects, our findings suggest that it may constitute another facet of the highly complicated processes for central cardiovascular regulation.

Heart rates usually decrease following an ICV injection of carbachol in conscious rats. $1,2,20$ Therefore, vagal tone should be increased because sympathetic nerve impulses would not be suppressed. A marked increase in systemic blood pressure may account for the fact that a baroreceptor reflex causes a fall in the heart rate.

$\mathrm{Wu}$ and $\mathrm{Wei}^{21}$ tried to produce neurogenic hypertension by infusing substances continuously with osmotic minipumps into the lateral ventricles of rats. Only carbachol was able to produce sustained hypertension for more than one week, which suggests that a central cholinergic mechanism plays a crucial role in regulating the blood pressure. Our findings suggest that increased sympathetic nerve activity is involved, but the release of pituitary hormones plays a greater role in blood pressure elevation in carbachol-induced pressor responses.

\section{REFERENCES}

1. HOFFMAN WE, PHILLIPS MI: A pressor response to intraventricular injections of carbachol. Brain Res 105: 157, 1976

2. LANG WJ, RUSH ML: Cardiovascular responses to injections of choliomimetic drugs into the cerebroventricles of unanesthetized dog. $\mathrm{Br} J$ Pharmacol 47: 196, 1973

3. DAY MD, ROACH AG: Cardiovascular effect of carbachol and the other choliomimetics administered into the cerebral ventricles of conscious cats. Clin Exp Pharmacol Physiol 4: 431, 1976

4. BEAL AM, BLIGH J: Effect of intraventricular injection of transmitter substances and temperature on autonomic functions of conscious sheeps. J Physiol 294: 239, 1979

5. DE ROBERTIS E, DE IRALDI AP, DE LORES ARNAIZ RG, SALGANICOFF L: Cholinergic and non-cholinergic nerve endings in rat brain. I. Isolation and subcellular distribution of acetylcholine and acetylcholine esterase. $J$ Neurochem 9: 23, 1962

6. FELDBERG W, VOGT M: Acetylcholine synthesis in different regions of the central nervous system. J Physiol 107: 372, 1948

7. KNOX GV, CAMPBELL C, LOMAX P: The effects of acetylcholine and nicotine on unit activity in the hypothalamic thermoregulatory centers of the rat. Brain Res 51:215, 1973

8. BUCCAFUSCO JJ, BREZENOFF HE: Opposing influence on behavior mediated by muscarine and nicotine receptors in the rat posterior hypothalamic nucleus. Psycopharmacology 67: 249, 1980

9. SIMPSON JB, ROUTTENBERG A: The subfornic organ and carbacholinduced drinking. Brain Res 45: 135,1972

10. SWANSON LW, SHARPE LW: Centrally induced drinking: Comparison of angiotensin II- and 
carbachol-sensitive sites in rats. Am J Physiol 225: 566,1973

11. SLADEK CD, JOYNT RJ: Characterization of cholinergic control of vasopressin by the organcultured rat hypothalomoneurohypophyseal system. Endocrinology 1043: 659, 1979

12. HOFFMAN WE, SCHMID PG, PHILLIPS I: Central cholinergic and noradrenergic stimulation in spontaneously hypertensive rats. J Pharmacol Exp Ther 206: 644, 1978

13. VANDEPUTTE-VAN MG, PETERS G: Effects of administration of cholinergic drugs into the 3rd ventricle of goats on water diuresis. Arch Int Pharmacol 206: 405, 1973

14. BEAL MA: Changes in renal hemodynamic and electrolyte excretion after intraventricular infusion of carbachol in conscious sheeps. Quarterly J Exp Pharmacol 65: 159, 1978

15. BUCCAFUSCO JJ, BREZENOFF HE: Pharmacological study of cholinergic mechanism within the rat posterior hypothalamic nucleus which mediates a hypertensive response. Brain Res 165: 295,1979
16. WEEKS JR, JONES JA: Routine direct measurement of arterial pressure in unanesthetized rats. Proc Soc Exp Biol Med 104: 646, 1960

17. PELLEGRINO LJ, PELLEGRINO AS, CUSHMAN AJ: A stereotaxic atles of the rat brain, 2nd ed., New York, Appleton-Century-Crofts, 1979

18. HOFFMAN WE, PHILLIPS MI, SCHMID PG, FALCON J, WEET JF: Antidiuretic hormone release and the pressor response to central angiotensin II and cholinergic stimulation. Neuropharmacology 16: 463, 1976

19. SINHA JN, DHAWAN KN, CHANDRA O, GUPTA G: Role of acetylcholine in central vasomotor regulation. Can J Physiol Pharmacol 45: 503, 1967

20. CAPUTI AP, BREZENOFF HE: Cardiovascular effect produced by choline injected into the lateral cerebral ventricle of the unanesthetized rat. Life Sci 26: 1029, 1980

21. WU MS, WEI ET: Infusions of chemicals into the brain and the development of elevated blood pressure with cholinergic drugs. Life Sci 30: 1537, 1982 